\title{
A natureza do Estado e sua relação com a Sociedade Civil frente a crise do Covid-19
}

\author{
The nature of the State and its relationship with civil society in the face of the Covid-19 crises \\ La naturaleza del Estado y su relación con la sociedad civil ante las crisis del Covid-19
}

Recebido: 28/06/2021 | Revisado: 05/07/2021 | Aceito: 06/07/2021 | Publicado: 07/07/2021

\author{
Jacqueline D'Arc Oliveira Silva \\ ORCID: https://orcid.org/0000-0001-6473-6365 \\ Universidade Federal da Bahia, Brasil \\ E-mail: Jacqueline.darc@gmail.com
}

\begin{abstract}
Resumo
Com a pandemia do Covid-19 surge uma reflexão acerca do papel do Estado e sua relação com a sociedade civil. Com isso, torna-se indispensável discutir o papel do Estado Brasileiro em combater a crise sanitária em questão. O presente artigo discorre sobre o conceito de Estado e Sociedade Civil junto com uma reflexão sobre o papel do Estado no cenário de pandemia, a importância da sociedade civil e os entraves e desafios tanto do ponto de vista estatal quanto do social. Para tanto, foi adotado como método de abordagem o dedutivo para entender a importância dos programas de transferência de renda além de revelar a natureza do Estado e seus impactos sociais principalmente no que tange a população de baixa renda. Contudo, o estudo apresentado revela a importância e a ausência de um plano nacional de combate a pandemia, assim como um estudo de médio e longo prazo sobre a necessidade de um auxílio financeiro para a população em situação de vulnerabilidade social.
\end{abstract}

Palavras-chave: Estado; Sociedade; Covid-19.

\begin{abstract}
With the Covid-19 pandemic comes a reflection on the role of the State and its relationship with civil society. Thus, it is essential to discuss the role of the Brazilian State in combating the health crisis in question. This article discusses the concept of State and Civil Society together with a reflection on the role of the State in the pandemic scenario, the importance of civil society and the obstacles and challenges both from a state and social point of view. Therefore, the deductive approach was adopted as a method of approach to understand the importance of income transfer programs, in addition to revealing the nature of the State and its social impacts, especially with regard to the low-income population. However, the study presented reveals the importance and absence of a national plan to combat the pandemic, as well as a medium and long-term study on the need for financial assistance for the population in a situation of social vulnerability.
\end{abstract}

Keywords: States; Society; Covid-19.

\begin{abstract}
Resumen
Con la pandemia de Covid-19 llega una reflexión sobre el papel del Estado y su relación con la sociedad civil. Por tanto, es fundamental discutir el papel del Estado brasileño en la lucha contra la crisis de salud en cuestión. Este artículo discute el concepto de Estado y Sociedad Civil junto con una reflexión sobre el rol del Estado en el escenario pandémico, la importancia de la sociedad civil y los obstáculos y desafíos tanto desde el punto de vista estatal como social. Para ello, se adoptó el enfoque deductivo para comprender la importancia de los programas de transferencia de ingresos, además de revelar la naturaleza del Estado y sus impactos sociales, especialmente con respecto a la población de bajos ingresos. Sin embargo, el estudio presentado revela la importancia y ausencia de un plan nacional de combate a la pandemia, así como un estudio de mediano y largo plazo sobre la necesidad de asistencia financiera para la población en situación de vulnerabilidad.
\end{abstract}

Palabras clave: Estado; Sociedad; Covid-19.

\section{Introdução}

A crise sanitária provocada pelo surto de pandemia da Covid-19 se configura como um dos maiores desafios da história recente do Brasil e exige uma reflexão acerca do papel do Estado. Atrelado a isso, esse desafio finalmente possibilitou evidenciar o debate da desigualdade social e a urgência de políticas públicas sob novo enfoque. Para tanto, o objetivo deste artigo é analisar a natureza do Estado e sua relação com a sociedade civil frente a grandes crises como a pandemia da Covid19. 
Dessa forma, diante de uma dicotomia entre preservar renda e a saúde da população, emerge a reflexão sobre o papel do Estado brasileiro no combate à crise ocasionada pela pandemia do covid-19 torna indispensável discutir o papel do Estado Brasileiro em combate a crise sanitária em questão. Logo, as ações estatais não devem se limitar a medidas sanitárias, mas demonstrar seu papel principalmente para os cidadãos mais vulneráveis, garantir a continuidade de empresas, injetar recursos na economia no cenário de recursos escassos as fontes que financiaram essas medidas são também incertas. Apesar do contexto de desafio mundial, o Estado é o principal agente, seja como estabilizador da economia, investidor em infraestrutura físicasocial, protetor dos mais vulneráveis, provedor de serviços e empreendedor.

Para subsidiar a discussão teórica e conceitual foram tomadas como referência o conceito de Estado e Sociedade Civil. Em relação ao conceito de Estado foi tomada por base a construção teórica de Lemke, Bresser. Já no cerne da Sociedade Civil foi concebida por Vaz, Bisneto, Santos e Cavet.

$\mathrm{O}$ trabalho em questão está organizado em três importantes eixos. Sendo que no primeiro discorre-se sobre o conceito de Estado e Sociedade Civil. O segundo eixo faz uma reflexão sobre o papel do Estado no cenário de pandemia, a importância da sociedade civil e os entraves e desafios tanto do ponto de vista estatal quanto do social. A última parte apresenta as considerações finais sobre a análise realizada.

\section{Metodologia}

Quanto ao percurso metodológico para o presente estudo, foi adotado como método de abordagem o dedutivo, uma vez que contribui para a análise e compreensão da importância dos programas de transferência de renda além de revelar a natureza do Estado e seus impactos sociais principalmente no que tange a população de baixa renda.

Para tanto a pesquisa foi fundamentada através do levantamento bibliográfico com a consulta de livros, artigos, teses e dissertações para subsidiar a discussão conceitual sobre Estado e Sociedade Civil, além de procurar entender o contexto da criação do auxílio emergencial durante a pandemia do Covid-19, com método de abordagem qualitativa, para melhor conhecer um fenômeno, ou seja, a influência da transferência de renda direta no contexto da pandemia do Covid-19. Sendo assim, o trabalho em questão tomou como referência uma investigação documental, para identificar estudos semelhantes sobre os programas de transferência de renda, de uma maneira geral, além da trajetória histórica e contribuições.

\section{Resultados e Discussão}

A análise desenvolvida tomou por base o papel do Estado e da sociedade civil no contexto da crise sanitária mundial provocada pelo vírus Sars-cov-2. Logo, tornou-se contundente enfatizar uma importante medida tomada pelo Estado para amenizar as consequências, provocadas pela epidemia ressaltada, principalmente para a população em situação de vulnerabilidade social através da adoção de um auxílio financeiro emergencial. Entretanto, cabe questionar em quais circunstâncias tal medida foi adotada e os fatores que foram considerados, uma vez que, ainda não foi instituída uma política nacional de combate ao coronavírus.

\subsection{Conceito de Estado e Sociedade Civil: uma análise no contexto da crise sanitária mundial de 2020}

Por se tratar de uma concepção complexa e de acordo com o objetivo da reflexão proposta, serão destacadas três importantes acepções de Estado. Sendo que, a primeira, trata-se da abordagem do Estado moderno, a segunda ponderação enfatiza a natureza do Estado desenvolvimentista e a terceira abordagem ressalta a ação estatal no viés neoliberal. Do mesmo modo é relevante destacar a relação do Estado com a sociedade civil. A partir de tais colocações conceituais será possível 
compreender o papel do Estado ou que deveria desempenhar mediante um desafio global como a atual pandemia do coronavírus.

O Estado moderno, resultado das transformações geradas a partir da Revolução Francesa, é fundado em um princípio racional de organização e orientado pelos princípios da liberdade e da igualdade perante a lei. Sendo assim, o Estado Moderno constitui uma comunidade humana que objetiva coordenar a sociedade civil. De um lado, a sociedade civil nutre o Estado através de impostos e no cumprimento de suas leis, de outro, o Estado detém o monopólio do poder (político e de polícia visando regular a manifestação individual destes poderes pelos indivíduos na sociedade) e administração de modo a manter a ordem e assistir a sociedade dentro de uma área territorial (Lemke, 2017).

Ao longo do tempo a noção de Estado foi modificada e o seu papel de interventor na atividade econômica e na sociedade se mostrou essencial especialmente em tempos de crise. Na teoria Keynesiana o Estado deveria intervir na economia sempre que fosse necessário, com o intuito de evitar retração econômica e garantir emprego e desenvolvimento. Segundo Luiz Carlos Bresser-Pereira um Estado é desenvolvimentista quando:

[...] (a) considera o crescimento econômico como seu principal objetivo; (b) intervém de forma moderada no mercado, planejando o setor não competitivo da economia e adotando políticas industriais estratégicas; (c) adota uma política macroeconômica ativa, limitando os déficits orçamentários e em conta corrente e assegurando que os cinco preços macroeconômicos atinjam o nível "certo", em particular a taxa de câmbio; e (d) possui o apoio político de uma coalizão de classes para o desenvolvimento, formada por empresários, trabalhadores, funcionários da burocracia pública e setores da antiga classe dominante que exercem poder político e apoiam uma estratégia nacional de desenvolvimento, coalizão que, assim, se opõe a uma coalizão liberal-conservadora composta por capitalistas rentistas, financistas e os interesses estrangeiros. (Bresser, 2016, p. 237)

Contrapondo a teoria Keynesiana do Estado desenvolvimentista temos o Estado Neoliberal, tido como "estadomínimo" que as teorias políticas liberais concebem as funções do Estado essencialmente voltadas para a garantia dos direitos individuais, sem interferência nas esferas da vida pública e, especificamente, na esfera econômica da sociedade.

Para além de uma entidade, o Estado se constitui como força atuante na sociedade e cujas decisões impactam diretamente na qualidade de vida dos cidadãos e no ambiente criado para a prática das atividades sociais. Logo, a Sociedade Civil e o Estado se conectam de maneira quase indissociável. No decorrer do desenvolvimento da vida em sociedade surgem Estados complexos e instituições sociais cada vez mais determinantes e autônomas, mas que também são determinados pelo conjunto da organização social (Vaz, 2019).

\subsection{O papel do Estado na gestão de crise do Coronavírus: auxílio emergencial e ausência de uma política nacional de combate ao Coronavírus}

Situações atípicas como uma pandemia exigem uma maior intervenção do Estado para amenizar as mazelas sociais que escancaram as desigualdades existentes, seja no aumento no número de desempregados, na precariedade do acesso à saúde pela população mais carente ou ainda através de subsídios como auxílios emergenciais. É neste contexto que se vislumbra a ideia de administração pública as quais desempenham atividades estatais com alguma autonomia em relação ao poder político. É também neste ambiente que se pode cogitar sobre a responsabilidade dos entes estatais, uma vez reconhecida sua personalidade jurídica, que não se confunde com as pessoas dos governantes e administradores.

A Pandemia causada pelo COVID-19 suscitou reflexões nos âmbitos sociais, econômicos e políticos, sobretudo com a imposição do distanciamento social pela LEI ${ }^{\circ}$ 13.979/2020. Neste contexto, o papel do Estado, para além de gestor de recursos, compreende o de tomador de decisões cruciais no enfrentamento desta crise sanitária e suas ações e omissões, acertos e desacertos decorrentes da postura adotada impacta toda a sociedade, especialmente em relação à garantia de direitos fundamentais aos cidadãos como o acesso à saúde (Bisneto, et al., 2020). 
Em situações como uma pandemia, é evidente a necessidade da coordenação dos recursos da Sociedade Civil com os do Estado. Um mapeamento realizado pela organização PonteAponte mostrou que 2 meses após o primeiro caso registrado no Brasil 450 ações de OSC's (Organizações da Sociedade Civil) já haviam sido registradas. Estas ações vão desde levantamento de fundo, recursos, mobilização de voluntários, campanhas educativas, dentre outros. Parcerias entre as OSC e o Estado estão presentes também em repasses de verbas, como demonstram os dados de Escudero (2020), entre 2010 e 2018, o governo federal repassou um total de $\mathrm{R} \$ 118,5$ bilhões às OSCs.

Assim, na tentativa de conter a rápida transmissão da doença, autoridades de diferentes nacionalidades promoveram uma série de medidas como o isolamento social, fechamento de instituições de ensino, estabelecimento comercial e qualquer evento que pudesse gerar aglomerações de pessoas a fim de evitar a propagação da doença. Com a exposição desnecessária ao coronavírus, que é um vírus de fácil transmissibilidade, mesmo com o surgimento de vacinas, medidas como essas se fazem necessárias devido a incapacidade de o sistema de saúde acolher e tratar os infectados.

Nesse sentido, foi necessário adotar medidas urgentes em duas direções: por um lado, conter a pandemia, salvando vidas; por outro lado, buscar estimular a economia para evitar o caos econômico e social. Entretanto, a crise causada pela pandemia deixa claro o paradoxo da sobrevivência: ao mesmo tempo que defende uma concepção liberal nos moldes de "Laissez-faire" - deixar o mercado agir sem interferências das ações do governo; por outro lado, também mostra a importância do Estado enquanto agente decisivo para implantar políticas efetivas capazes de salvar vidas e aquecer as atividades econômicas. É necessário que o Estado intervenha na forma de prover recursos mínimos para a sociedade sobreviver ao isolamento, principalmente aqueles desprovidos de qualquer rendimento.

Com os inevitáveis danos econômicos com a suspensão radical das atividades de inúmeros setores produtivos e de serviços e o tímido consumo dos cidadãos, motivado pela pandemia do novo Coronavírus, e a urgência de instrumentos de combate à miséria impõe como necessária a criação de estratégias de políticas administrativas e econômicas para garantir a renda mínima à população mais vulnerável, como, também, para a população que, por causa da crise, encontra-se, temporariamente, sem renda do trabalho de natureza microempreendedora ou informal.

Nesse cenário de emergência, muitos países propuseram uma série de ações sociais tentando alcançar os grupos mais vulneráveis. Crescendo a demanda por ações estatais voltadas à proteção social dos que se encontram fora do mercado de trabalho ou vivendo sua precarização. O especialista independente da ONU, Juan Pablo Bohoslavsky, fala sobre a implantação de uma renda mínima universal de emergência, uma transferência direta de dinheiro, sem intervenção de grandes empresas ou bancos em benefício de pessoas.

Apesar da gravidade do problema, reconhecida pelas autoridades nacionais e internacionais, as formas de ajuda emergencial, que recomendaria mais bom senso às autoridades, foram marcadas por conflitos de interesses, nem sempre os interesses daqueles mais necessitados e para os quais as medidas estão direcionadas.

Diante da gravidade e do estado de calamidade imposto pelo agravamento da pandemia, a proposta do Auxílio Emergencial é pautada pelo princípio da dignidade da pessoa humana, previsto na Constituição Federal de 1988, com o seguinte preâmbulo:

"O Auxílio Emergencial é um benefício financeiro destinado aos trabalhadores informais, microempreendedores individuais (MEI), autônomos e desempregados, e tem por objetivo fornecer proteção emergencial no período de enfrentamento à crise causada pela pandemia do Coronavírus - COVID 19.”

Usando a referência do ativista social, o Senador Eduardo Suplicy, responsável pela Lei no 10.835, de 8 de Janeiro de 2004, que refere-se a instituir a renda básica de cidadanias para todos os brasileiros residentes no País e estrangeiros residentes há pelo menos 5 (cinco) anos no Brasil, receberem um benefício monetário suficiente para atender às despesas mínimas de 
cada pessoa com alimentação, educação e saúde, considerando para isso o grau de desenvolvimento do País e as possibilidades orçamentária.

Desse modo, os governadores e a sociedade civil clamaram para o governo federal implantar com urgência um projeto de renda básica no combate à pandemia. Uma instituição de renda básica para amparar a população economicamente vulnerável. Para a equipe do ministro da Economia, Paulo Guedes, existia uma proposta para um voucher entre R\$200 e $\mathrm{R} \$ 300$ para trabalhadores informais. Com o aumento expressivo nos números de mortes diárias por conta da Covid-19, um número alarmante de pessoas a menos trabalhando nos últimos meses e a expectativa otimista da vacina é só em dezembro. Surgiu uma pressão por parte dos governadores e sociedade, propondo valores e alcance maiores do que a proposta original do governo.

Com a inspiração da proposta apresentada por Suplicy, em 1991, e pela Lei nº 10.835/2004, o programa de renda básica emergencial aprovado no Congresso é destinado, particularmente, a trabalhadores informais, que são o grupo mais vulnerável à crise do novo Coronavírus. Os trabalhadores informais são trabalhadores que não possuem acesso à rede de proteção social ou amparos legais que garantam uma estabilidade na sua renda como o FGTS, seguro-desemprego, licença saúde. A maior parte desses serviços ofertados aos trabalhadores dependem de terem pessoas circulando nas ruas para usufruir dos seus serviços. E com o isolamento social houve uma queda na demanda por seus bens e serviço e suas rendas prejudicadas.

De acordo com a proteção social definida pela PNAS/2004, e o conceito de organização do Sistema Único de Assistência Social-SUAS

"Os serviços socioassistenciais são organizados segundo as referências de: vigilância social, proteção social e defesa social e institucional. Umas das garantias da proteção social é a Segurança de Sobrevivência: através de benefícios continuados e eventuais que assegurem: proteção social básica a idosos e pessoas com deficiência sem fonte de renda e sustento; pessoas e famílias vítimas de calamidades e emergências; situações de forte fragilidade pessoal e familiar, em especial às mulheres chefes de família e seus filhos"

\section{Conforme estabelece o NOB/-SUAS}

"A segurança social de renda, de competência da Assistência Social, é operada através de concessão de bolsasauxílios financeiros sob determinadas condicionalidades, com presença (ou não) de contrato de compromissos; e da concessão de benefícios continuados, nos termos da lei, para cidadãos não incluídos no sistema contributivo de proteção social, que apresentem vulnerabilidades decorrentes do ciclo da vida e/ou incapacidade para a vida independente e para o trabalho" (Secretaria Nacional de Assistências Social).

Apesar dos esforços empreendidos por estados e municípios, o subsídio emergencial desferido pelo governo federal é insuficiente e cabe o seguinte questionamento: Por que não adotar uma política nacional de combate ao coronavírus? Pois, se trata de um problema sanitário em escala global que tem desafiado as economias centrais. E no contexto das economias latinoamericanas, marcadas pela histórica desigualdade socioeconômica, só acentuará esse cenário e portanto deve-se pensar em ações de médio à longo prazo e não em um auxílio temporário.

Contudo, vale ressaltar que no atual estágio do processo de globalização as pandemias se tornarão recorrentes devido a chamada "compressão do espaço-tempo", expressão que ganhou notoriedade nos estudos de David Harvey. Logo, não apenas o fluxo de pessoas e mercadorias foi potencializado em uma escala de tempo cada vez menor, mas as ondas pandêmicas também. Destarte, outro fator relevante se remete a natureza do Estado, onde cabe enfatizar as consequências da supressão do Estado de bem estar social e as consequências da adoção de um modelo de "Estado de exceção" que pode despir a ação estatal de seu caráter social conduzindo para o que Achille Mbembe denominou de "necropolítica". 


\subsection{O papel da sociedade civil e os desafios da administração do estado federativo brasileiro no contexto da Covid-19.}

Através de iniciativas populares surgem organizações que buscam preencher as lacunas deixadas pela atuação do Estado, muitas vezes invisíveis em um contexto macro. As organizações da sociedade civil (OSCs) são entidades nascidas da livre organização e da participação social da população em regimes democráticos contemporâneos que desenvolvem ações de interesse público sem visar ao lucro.

No Brasil, elas tratam dos mais diversos temas e exercem atividades de interesse coletivo nos setores mais variados da sociedade, entre eles: saúde, cultura, esporte, assistência social, educação, agricultura familiar, defesa dos direitos de minorias (portadores de deficiência física, povos indígenas, quilombolas, população LGBT etc.).

Segundo o Mapa das OSCs IPEA (2020), atualmente, são 781.895 organizações formais e ativas exercendo ações em território brasileiro - espalhadas por todos os 5.570 municípios (ESCUDERO, 2020). A Pandemia trouxe um novo cenário e possibilitou o questionamento do status quo, reinventar instituições e práticas estabelecidas. Estes questionamentos podem gerar experimentações na interface entre o poder público, Estado e a Sociedade civil.

A existência plena da sociedade civil está pautada em alguns princípios como a autonomia em relação ao Estado, ao espaço de livre circulação de idéias (liberdade dos meios de comunicação, transporte e etc.) e amparo jurídico dentre outros para garantir a sua existência plena.

Embora crítica, a situação urgente imposta pela pandemia pode gerar experimentações e novos meios de interface entre sociedade civil, Estado e administração pública. No Brasil epicentro da pandemia - com aumento exponencial dos casos e das mortes pelo coronavírus - e internacionalmente reconhecido como um dos piores exemplos de governança da crise alguns aspectos como: (1) colapso gradativo dos sistemas de saúde de vários estados; (2) falta de coordenação, de comunicação e os conflitos recorrentes entre os poderes e os níveis de governo; (3) profunda desigualdade territorial, de renda, de condições de vida e de acesso aos serviços públicos de saúde e de proteção social; (4) formalismo, déficit de cobertura e falta de orçamento para as políticas públicas de saúde e de proteção social; (5) escalada do autoritarismo, falta de transparência e polarização política, amplificadas pela posturas do presidente e do alto escalão de seu governo frente à pandemia são fatores que demonstram vulnerabilidades do Estado e que têm o potencial de agravar a situação no país.

A pandemia do Covid-19 acentua na esfera política-institucional uma crise de administração no que tange a dimensão federativa manifestando de diversas formas nas políticas públicas como no entraves de articulação intergovernamental; dificuldades de execução e integração de ações e serviços em tempo hábil, como também, no protagonismo de alguns governos e negligência, negacionismo e omissão de outros.

O poder decisório do Estado na dicotomia entre o crescimento econômico e a assistência social é um ponto de desencontro. A estrutura do SUS em construção a 3 décadas e pensado para funcionar na dimensão territorial do Brasil gera dúvidas quanto a performance governamental federal, pois negações, desinformações, competição intergovernamental, dentre outros demonstram um descaso que levou o Brasil ao epicentro desta pandemia (Censon \& Barcelos, 2020).

Com a piora da pandemia e o colapso no sistema de saúde na maioria das cidades brasileiras e os conflitos entre o presidente da República, governos e prefeitos tornaram mais exacerbados, dificultando a capacidade de resposta do Estado e, com isso, prejudicando a transparência e aumentando o desencontro de informações a respeito do Covid-19.

Para entender as dificuldades de resposta do Estado brasileiro no contexto da pandemia faz necessário olhar para a existência de grandes desigualdades socioespaciais e, principalmente, o entrave de conflitos políticos entre os governos.

A desigualdade do Brasil além de alarmante é uma característica mais marcante. É possível identificar discrepâncias entre as regiões do país, expressada em diferentes dimensões através de indicadores sociais, acesso à infraestrutura e econômicos, que impactam no acesso a assistência adequada requerida pela pandemia como os leitos de terapia intensiva. Em 
frente a essa desigualdade nas condições dos estados e municípios, o enfrentamento dessa disparidade exige um papel ativo do âmbito federal e que com os embates travados no governo faz permanecer restrito no âmbito da pandemia.

Com as grandes mudanças ideológicas de governo na atual gestão, o embate político no contexto atual decorre da divergência e disputas partidárias, apresentando assim o cenário de instabilidade e conflitos. Com a chegada da crise sanitária as dificuldades de administração no âmbito do governo federal aumentaram, culminando em duas trocas do Ministro da Saúde, aumento das diferenças de posições entre os governos federais, estaduais e municipais no que tange a medida de enfrentamento da pandemia, como também entre o governo e a sociedade (sociedade científica e movimentos sociais), garantindo a certeza da dificuldade no enfrentamento da pandemia.

Com a dificuldade de ações, o STF decidiu por unanimidade que estados e municípios possuem autonomia para criar estratégias diversas e articuladas e para decidir sobre o isolamento social, com o intuito de evitar que a pandemia prolongue seu tempo de duração e consequentemente as consequências devastadoras nas áreas econômicas, sociais e humanitárias. Porém, mesmo com a autonomia e a implementação de iniciativas inovadoras para o enfrentamento da Covid-19, permanecem insuficientes, sem um trabalho efetivo e um alinhamento com o governo federal em prol de um objetivo comum.

\section{Conclusão}

O Brasil é um país federativo, continental e desigual e, com isso, algumas estratégias devem ser variadas entre as regiões, estados e municípios do Brasil. Porém, dadas as características da federação brasileira, a variedade de respostas requer um papel ativo do governo federal e o alinhamento do governo com as demais escalas de liderança, a repartição clara de responsabilidades e competências gestoras entre as demais escalas do governo, cooperação entre diferentes grupos de sociedades (científica e movimentos sociais) no controle da Covid-19.

É notório que as medidas tomadas não contemplam toda a sociedade civil. O Estado neoliberal na atual conjuntura da política brasileira apresenta ações limitadas permitindo que o Coronavírus se torne um grave problema social no país.

Contudo, o estudo apresentado revela a importância e a ausência de um plano nacional - existem uma superficialidades das reflexões políticas onde as agendas são resolvidas de forma pontual e as agendas gerais caminham ao sabor dos acontecimentos de combate a pandemia, assim como um estudo de médio e longo prazo sobre a necessidade de um auxílio financeiro para a população em situação de vulnerabilidade social (em que o valor e o tempo desse auxílio foram baseados).

\section{Referências}

Arcoverde, A. C. B. Serviço Social e Questão Social na Globalização. In: Revista Serviço Social \& Realidade, 17, $102-124$

Almeida, C., Luchmann, L., \& Martelli, C. (2020). A pandemia e seus impactos no Brasil. Middle Atlantic Review of Latin American Studies, 4(1)

Alvarenga, A. A, et al. "Desafios Do Estado Brasileiro Frente À Pandemia Pela Covid-19: O Caso Da Paradiplomacia Maranhense."

Alves, M. A. O conceito de sociedade civil: em busca de uma repolitização. Organ. Soc., 11, 141-154 <http://www.scielo.br/scielo.php ?script=sci_arttext\&pid=S1984-92302004001000141\&lng=en\&nrm=iso $>$ https://doi.org/10.1590/1984-9110010.

Andion, C. Atuação da sociedade civil no enfrentamento dos efeitos da COVID-19 no Brasil. Rev. Adm. Pública, 54, 936-951 <http://www.scielo.br/scielo.php?script=sci_arttext\&pid=S0034-76122020000400936\&lng=en\&nrm=iso>. https://doi.org/10.1590/0034-761220200199.

Bosneto, C. D. et al. Responsabilidade civil do Estado e pandemia da COVID-19. Revista IBERC, 3, 71-92

Brasil, Norma Operacional Básica NOB/SUAS. http://www.assistenciasocial.al.gov.br/sala-de-imprensa/arquivos/NOB-SUAS.pdf.

Brasil, Discursos e notas taquigráficas. Câmara dos Deputados- DETAQ. 17/03/2020. https://www.camara.leg.br/internet/sita qweb/TextoHTML.asp?etapa=11\&nuSessao=59468\&hrInicio=10:49\&dtReuniao=17/03/2020\&dtHorarioQuarto=10:49\&dtHoraQuarto=10:49\&Data=17/03/2 020 .

Bresser-Pedreira, L.C. (2019) Modelos de estado desenvolvimentista. Revista de Economia, UFPR 40, 231-256 
Research, Society and Development, v. 10, n. 8, e49310817650, 2021

(CC BY 4.0) | ISSN 2525-3409 | DOI: http://dx.doi.org/10.33448/rsd-v10i8.17650

Bobbio, N.(1995). Estado, governo, sociedade: para uma teoria geral da política. Paz e Terra, 4 .ed..

Censon, D. \& Barcelos, M. O Papel Do Estado Na Gestão Da Crise Ocasionada Pela Covid-19: Visões Distintas Sobre Federalismo E As Relações Entre União E Municípios. Revista Brasileira de Gestão e Desenvolvimento Regional, 16, <https://www.rbgdr.net/revista/index.php/rbgdr/article/view/5977>.

Escudeiro. C. (2020). Os Impactos da pandemia de Covid-19 nas Organizações da Sociedade Civil: conjuntura, desafios e perspectivas. 2020.

Hofling, E. (2001). Estado e políticas (públicas) sociais. Cadernos Cedes, 21, -41.

Instituto de Estudos para Políticas de Saúde, (2020). "Vulnerabilidades da População Brasileira à COVID-19: Desafios para a flexibilização do Distanciamento Social’. https://ieps.org.br/wp-content/uploads/2020/05/NT9-IEPS.pdf

Lemke, W. C. (2017) As Ruínas Do Estado Moderno E A Síndrome De Inefetividade Dos Direitos Humanos.

Lima, L. D. A., Mendes. M. P., \& Machado. C. V.. "Crise, condicionantes e desafios de coordenação do Estado federativo brasileiro no contexto da COVID19." Cadernos de Saúde Pública 36 (2020): e00185220.

Mbembe, A. (2020) Necropolítica. Melusina. Rede Brasil, Transferência de renda: o direito de pensar em futuro. Rede Brasil atual. 2014. https://www.redebrasilatual.com.br/revistas/2014/09/transferencia-de-renda-o-direito-de-pensar-em-futuro-804/ .

Silva, M. L. da \& Silva, R. A. Economia Brasileira Pré, Durante E Pós-Pandemia Do Covid-19: Impactos E Reflexões. 2020. https://www.ufsm.br/app/uploads/sites/820/2020/06/Textos-para-Discuss\%C3\%A3o-07-Economia-Brasileira-Pr\%C3\%A9-Durante-e-P\%C3\%B3s-

Pandemia.pdf.

Vaz, M. R. Teorias sobre o Estado moderno e contribuições para a análise das políticas educacionais. Caderno Eletrônico de Ciências Sociais: Cadecs, 7, 7189 